\title{
Extraction and Inversion of deciduous broad-leaved forest Based on HJ-CCD Remote Sensing Data
}

\author{
Wang Yan, Tian Qingjiu*, Huang Yan \\ International Institute for Earth System Science, Nanjing University, Nanjing, China
}

\begin{abstract}
In this paper, Chuzhou area in Anhui province was taken as the study area, and deciduous broad-leaved forest as the study object. The NDVI was obtained based on HJ-CCD remote sensing images acquired on April 1,2012 and May 4,2012 when broad-leaved forest was respectively in leaf expansion and flowering. Next, combined with the position information collected in field, the recognition model for deciduous broad-leaved forest was proposed with NDVI difference rate between leaf expansion and flowering. And then deciduous broad-leaved forest in the study area was extracted effectively and the result was verified. Finally, poplar forest was taken as an example, and then the LAI inversion was carried out and the result was verified by using the LAI data obtained in field combined with poplar forest data information collected at the plot. The results show the validity of NDVI difference rate recognition method proposed in this paper and also verify the advantages of LAI inversion for poplar forest using HJ-CCD data .
\end{abstract}

Key words-HJ-CCD; deciduous broad-leaved forest; NDVI; poplar forest ; LAI

\section{INTRODUCTION}

The two satellites of $\mathrm{HJ}$ in China are carried with two identical CCD cameras, and CCD camera's revisit cycle is only 2 days after networking, which forms the data acquisition capabilities of obtaining the data in the same area each 2 days[1]. The revisit cycle has the advantage of tracking vegetation growth.

Different vegetation have different growth cycle and phonological rhythm, which can be reflected through spectral differences. Therefore, this difference can be taken as the departure point of vegetation identification[2]. So NDVI sequences under different phase conditions can reflect the seasonal changes of vegetation growth more accurately. The pixels with similar spectral characteristics of timing NDVI may be regarded as covered with the same vegetation type in the same area[3]. NDVI as the best indication of the vegetation growth status and vegetation coverage factor, its timing data has also become the basic means to carry out classification for large areas of vegetation and land cover based on bioclimatic characteristics[4,5,6].

Based on the characteristics of vegetation phenophase, this paper taked advantage of HJ-CCD image with short cycle revisit period to get the NDVI calculated from HJ-CCD remote sensing data. The recognition model about deciduous broad-leaved forest was constructed using NDVI difference rate between leaf expansion and flowering and fruit-bearing during which deciduous broad-leaved forest is growing at a high rate of speed. And then deciduous broad-leaved forest was extracted and validated. Finally, poplar forest was taken as an example and the LAI inversion was carried out, and then the result was verified and evaluated by using the LAI data obtained in field combined with poplar forest data information collected at the plot.

\section{II . STUDY SITE DESCRIPTION}

The study area is located in Chuzhou City, and Chuzhou $\operatorname{City}\left(31^{\circ} 51^{\prime}-33^{\circ} 13 \mathrm{~N}, 117^{\circ} 09^{\prime}-119^{\circ} 13^{\prime}\right)$ is located in the eastern part of Anhui Province, the western edge of the Yangtze River Delta. The city's landscape can be divided into three types, and they are hilly, downland, and plain. The total forest area of the city is 410 million $\mathrm{mu}$, the forest coverage rate is $20.5 \%$, and plantations accounts for more than 95\%. The type of community includes broad-leaved forest, coniferous forest and coniferous and broadleaf mixed forest. In each area type, poplar is cultivated, and poplar has become one of the main 
afforestation species in Chuzhou. According to the survey of forest resources in Chuzhou, black poplar category accounts for more than $80 \%$, which has an absolute advantage in the species structure. While acacia, neem, ailanthus, elm, maple and other fine native trees are scarce[7]. The wheat and rice are the main crops, while rapeseed and corn are scattered.

\section{STUDY METHODS}

\section{A. Remote Sensing Data Processing}

In this study, HJ-1A CCD Level 2 data of the HJ satellite were obtained on April 1, 2012 and May 4, 2012. Then the preprocessing was conducted and the NDVI was calculated.

\section{B. Poplar Fotest LAI Measurement and Data Processing}

Measurements used the LAI-2000 plant canopy analyzer manufactured by LI-COR company in USA. The A (above canopy)and B value (below canopy) are measured separately, in the open area and into the forest.

21 plots were set up at relatively flat places where the dominant tree species were simple and the area of poplar was larger than $90 \mathrm{~m} \times 90 \mathrm{~m}$. For each plot, 5 to 10 samples were chosen and three repeated readings of $\mathrm{B}$ for each sample were taken. And then the LAI of each samples was estimated by combing $\mathrm{A}$ with $\mathrm{B}$ that were most close in measure time. At last, the average LAI was computed for each sample plot.

\section{Deciduous Broad-leaved Forest Recognition and}

\section{Extraction}

Regional NDVI values increasing and decreasing periodically with time is a typical reflection of the vegetation growth cycle. All the vegetation types were in dormant period from early January to late March, while in growth season from early July to late August[8]. Therefore, phenological differences are not obvious in this time. In the middle of May to late June, coniferous and broad-leaved mixed forest, deciduous broad-leaved forest, wetland and grassland have been in growth season[8], and NDVI difference is not obvious. By comparison, the shapes of NDVI timing curves of deciduous forest, high coverage grassland and cropland were similar, and have the similar growing season range[9]. While the deciduous forest because of leaves falling and withering in wither, the NDVI values are low in January and February, and begin to rise from late March, then reach the highest value by the end of April[9].This feature is different from the grassland with high coverage and farmland. For the evergreen forest, NDVI values are higher within one year and have no large fluctuation[10], which are obviously different from deciduous forest. So the vegetation growth transition period from April to May can be chosen to study phenological differences of various vegetation. On the basis of the characteristics of NDVI, deciduous forest can be separated from vegetation.

Through field investigation, it was found that the main crop corresponding to the two periods in the study was wheat, while rapeseed distributed sporadically, so it was not be considered. The deciduous broad-leaved forest was at an early stage of sprout leaves in April, and growed rapidly with the temperature rising. After flowering, entered flowering and fruit-bearing period. Deciduous broad-leaved showed obvious differences in phenology in this time, and NDVI obviously changed. But for deciduous coniferous forest in study area, due to differences in growth patterns, the variation of NDVI was little.

Therefore, based on the above characteristics and growth phenology characteristics of deciduous broad-leaved forest, the recognition model was proposed. First, HJ1A-CCD remote sensing images on April 1, 2012 and May 4,2012 were acquired and processed to get NDVI corresponding to the two phase. And then combined with the 1:50000 topography and forest map and the location information of several vegetation distribution collected by field investigations, NDVI variation characteristics of different vegetations corresponding to the two periods in the study area were obtained. Finally, the recognition model was constructed by using NDVI on April 1,2012and May 4,2012. Several different vegetation types in three different growth conditions were shown in figure 1.

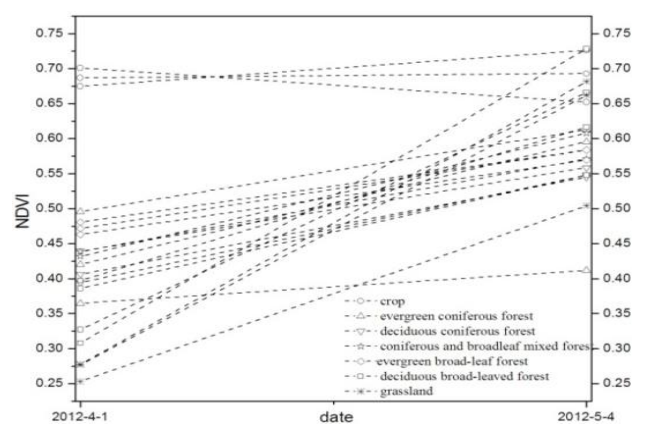

Fig.1 the change of NDVI in two phases about Poplar Plantation in the study area 
It can be seen from Figure 1 that NDVI of crops (mainly wheat) is relatively stable, and is in approximate saturation state. But the coniferous forest (evergreen and deciduous)is relatively hardy, and sprout earlier. So NDVI has been up to the range from 0.35 to 0.5 on April 1, and from0.5 to 0.6 on May 4. That is to say, the change of NDVI with time is not obvious, and the growth rate is smaller. NDVI of coniferous and broad-leaved mixed forest is in the range from 0.38 to 0.45 on April, and from 0.5 to 0.6 on May 4, so the change of NDVI with the time is also not too obvious. NDVI of evergreen broad-leaved forest both in the two phase are both larger, so the difference is also little. While for the deciduous broad-leaved forest, NDVI is in the range from 0.3 to 0.4 on April 1, and from 0.5 to 0.73 on May 4. It is found that the change of NDVI with time is obviously, and growth rate is large. But for the grassland, NDVI is in the range from 0.25 to 0.3 on April 1, and from 0.5 to 0.68 on May 4. It is obvious that the change trend of NDVI of grassland is similar to that of deciduous broad-leaved forest. But the ranges of NDVI corresponding to the two phases are different, which can be used to separate the deciduous broad-leaved forest from grassland. Therefore, with the threshold conditions of NDVI in the two phases, the NDVI difference rate between the two phase can be used to identify deciduous broad-leaved forest.

On the basis of these characteristics, the recognition model was constructed: $\mathrm{K}=\frac{(b 2-b 1) \times 1000}{d}$. Where b1 and b2 respectively stand for the NDVI on April 1 and May 4, and $d$ stands for days.

From Figure1, it is found that the NDVI defference rate in the two phases of crop, evergreen coniferous forest, deciduous coniferous forest, broad-leaved evergreen forest are obviously different from that of deciduous broad-leaved forest and grassland, so deciduous broad-leaved forest and grassland can be distinguished from them. While the NDVI difference rates of deciduous broad-leaved forest and grassland in the two phase are close. But the NDVI corresponding to the two phases are different, especially the NDVI On April 1 (b1). For deciduous broad-leaved forest: $b 1>0.3$, but for grassland: b1<0.3. Therefore, this constraint can be used to distinguish deciduous broad-leaved forest from grassland. In addition, in order to exclude the interference that results from the similar
NDVI difference rates of evergreen broad-leaved forest and deciduous broad-leaved forest, the NDVI of them in the two phase were compared. For deciduous broad-leaved forest: $\mathrm{b} 1<0.4$, but for evergreen broad-leaved forest: $b 1>0.4$. According to these conditions, they were distinguished.

Combined with figure 1 and the analysis of NDVI change characteristics in the two phases in the study area, the NDVI difference rate model was used. For deciduous broad-leaved forest: $0.3<b 1<0.4, b 2>0.5,6.45<\mathrm{K}<12.35$. Finally, deciduous broad-leaved forest in the study area was extracted accurately. The extraction result is shown in figure2.

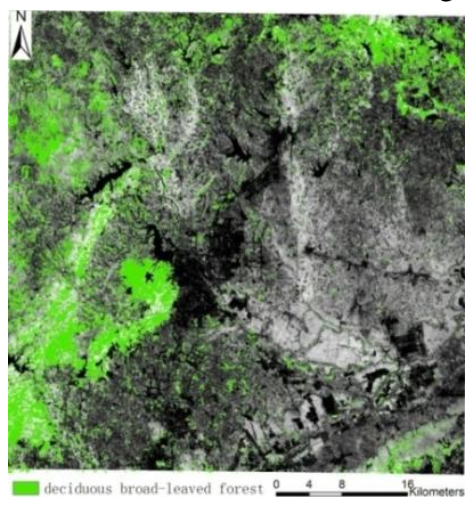

Fig .2 The extraction distribution of Deciduous Broad-leaved Forest in research area

In addition, the GPS information of 348 deciduous broad-leaved forest samples collected in field was used to evaluate the precision of the extraction., which was up to $83 \%$. This shows the validity and reliability of extraction using NDVI difference rate recognition model.

\section{LAI INVERSION OF POPLAR AND VALIDATION}

\section{A. LAI Inversion Model Construction}

There are many poplar forests in the study area. Moreover, the distribution of poplar forests is relatively concentrated, and most of them is planted forest. Therefore, poplar forest was taken as an example, and LAI inversion and validation was conducted.

The vegetation coverage in the study area wasn't saturated. Therefore, in this study, the HJ1A-CCD data acquired on May 4, 2012 was processed to get the NDVI. Combined with the LAI data measured in the field on May 6, 2012 and May 7,2012, the NDVI-LAI linear regression model was built, as shown in figure 3. 


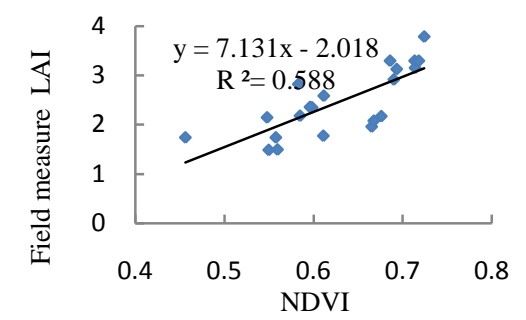

Figure 3 The NDVI-LAI linear regression model

It can be seen from Figure 3, the correlation coefficient $\left(\mathrm{R}^{2}\right)$ of NDVI-LAI linear model is 0.588 , which shows that the model is of high precision. Moreover, it also shows that NDVI has not been saturated. In addition, the time of LAI observations for deciduous broadleaf forest in the study area is in leaf - fruit period, when the LAI is larger, which is one of the reasons that ensure higher model accuracy.

\section{B. Poplar Forest LAI Inversion and Analysis}

Combined with the extraction of deciduous broad-leaved forest in the study area, the NDVI-LAI linear inversion model was used to the study area, and then LAI mapping was conducted and the result is shown in figure 4.

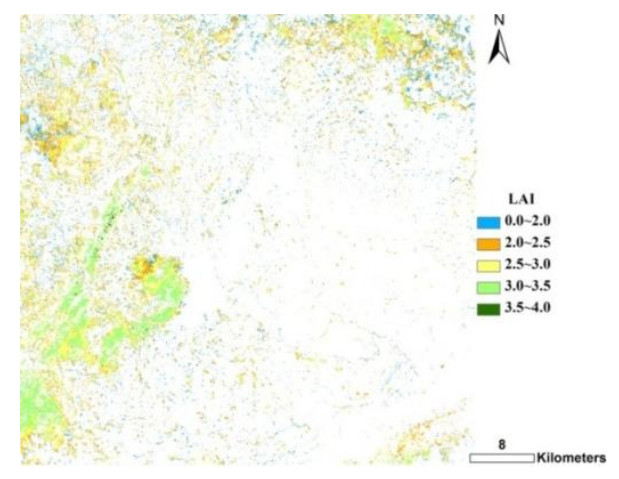

Figure 4 the distribution map of poplar forest LAI

It can seen from Figure 4, that the distribution of poplar forest LAI on May 4, 2012 is higher and centralizes in the western and northern. But the poplar forest is distributed sporadically in southern, eastern and central, where the LAI is relatively small. The central is the urban area of Chuzhou City, where forest land area is less, mainly industrial land and residential land. The south and east is mainly distributed with arable land and residential land, where poplar forest is few and in relatively poor growth. But on the whole, LAI was higher, mostly more than 2.5 , because poplar forest was in the vigorous growth period, when the leaves was of high density.

\section{Model Validation and Evaluation}

The establishment of LAI inversion models often appears to be "overfitting"[11], so it is necessary to verify the model using the field measured data. The NDVI-LAI model was verified with independent field measured LAI data on May 6 and 7, 2012, and the inversion result of model was compared with the field measured LAI data at the pixel scale.

By comparison of 36 sets of data, the max relative error is $39 \%$, and the $\min$ is $1 \%$, so the average relative error is $3 \%$, which shows that the model is of high accuracy. Therefore, the LAI of poplar forest can be estimated accurately using NDVI computed from $\mathrm{HJ}$ satellite images.

The 21 poplar plots are all located in the region where poplar forests are concentrated and dense. In addition, the time of LAI observations for deciduous broadleaf forest in the study area was in fruit-bearing period, when the LAI was larger. All of these reasons ensured lower error of inversion model. However, the data set with larger error, mainly resulted from the sparse poplar forest. Because the pixel included grass and shrub, which resulted in larger NDVI in these regions, and this caused the inversion LAI larger than the LAI measured in the field.

\section{CONCLUSION AND DISCUSSION}

Based on the growth characteristics of NDVI phonology for deciduous broad-leaved forest, with CCD remote sensing data of HJ satellite acquired on April 1, 2012 and May 4, and combined with data and information collected in the field, recognition model for deciduous broad-leaved forest was constructed and the result was verified in this paper. Finally, the poplar forest was taken an example to conducted LAI inversion and validation. For the very sparse deciduous broad-leaved forest, due to the effect of shrub and grass on the low layer, so the recognition method of NDVI difference rate can't make full use of its advantages, and it is still necessary to introduce other information to improve the precision of extraction. Due to the influence of pixel heterogeneity, the number of samples and the environment in the study area, when the recognition model in this paper is applied to other areas, recognizing and extracting need to be based on the specific situation in study area. The HJ satellite has the advantage of high resolution and short cycle of imaging, which 
can be made full use to study phenological characteristics of vegetation growth period. So that plant species identification can be carried out easily and quickly. Moreover, the status of vegetation growth can also be tracked.

\section{ACKNOWLEDGMENT}

This study was supported by the National Science and Technology Major Project (No.30-Y20A01-9003-12/13, China).

\section{REFERENCES}

[1] WANG Zhong-ting, LI Qing, TAO Jin-hua, et al. China Environmental Science, 2009, 29(9): 902-907.

[2] Defries R S, Townshend JR G.. International Journal of Remote Sensing, vol.15(17), 1994, pp. 3 567-3 586.

[3] SONG Yang, WAN You-chuan, SHEN Shao-hong, et al..Geomatics and Eomatics and Information Science of Wuhan University, vol. 32(5),2007, pp.406-409.

[4] Wardlow B D, Egbert S L, Kastens JH..Remote Sensing of Environment, vol.1082007, pp.290-310.

[5] ZHENG Yu-kun, ZHUANG Da-fang..Journal of the Graduate School of the Chinese Academy of Sciences, 2003,20(1): 62-68.

[6] Liu Aixia, Wang Jing, Lv Chun-yan. Progress in Geography, vol.25(2),2006, pp. 96-102.

[7] WANG Yu-song. Modern Agricultural Science and Technology, (3), 2009,pp.107-108.

[8] JIN Cui, ZHANG Bai, Song Kai-shan. Resources Science, vol. 31(3),2009, pp.515-522.

[9] GU Juan, LI Xin, HUANG Chun-lin..Advances in Earth Science, vol.25(3), 2010,pp.127-130.

[10] WANG Quan-fang, LI Jia. Resources and Environment in the Yangtze Basin, vol. 17(6) 2008,pp.866-871.

[11] PU Ruiling, GONG Peng. Hyperspectral remote sensing and its application. Beijing:: Higher Education Ptess,2000. 